\title{
Osteopontin as a marker for response to pegylated interferon Alpha-2b treatment in Chronic HCV Saudi patients.
}

\author{
Yousri Mostafa Hussein ${ }^{1,2}$, Ayman Alhazmi ${ }^{1}$, Saad Alzahrani ${ }^{3}$, Ahmad El-Askary,, \\ Abdulrahman Alghamdy ${ }^{5}$, Eman Bayomy ${ }^{4}$, Assmaa Selim ${ }^{6}$, Mohammed Alghamdy ${ }^{1}$
}

1. Medical Laboratories Department, Faculty of Applied Medical Sciences, Taif University, Saudi Arabia

2. Medical Biochemistry Department, Faculty of Medicine, Zagazig University, Egypt

3. Community Medicine Department, Faculty of Medicine, Taif University, Saudi Arabia

4. Medical Biochemistry Department, Damietta Faculty of Medicine, Al-Azhar University, Egypt

5. Community medicine, Faculty of Applied Medical Sciences, Taif University, Saudi Arabia

6. Histology and Cell Biology Departement, Faculty of Medicine, Zagazig University

\begin{abstract}
:
Background: Many recent studies support the idea that osteopontin (OPN) can be used to predict the success of pegylated interferon (PEG IFN) alpha-2b/ribavirin therapy in chronic HCV patients.

Objective: Our aim was to investigate the role of plasma OPN and its gene polymorphism at nt - 443 in response to PEG IFN in Saudi patients with chronic HCV.

Methods: Blood was collected from 87 patients with chronic hepatitis $C$ before treatment, then patients received PEG IFN $\alpha 2 \mathrm{~b}$ plus ribavirin combination therapy. Another 25 healthy subjects, matched for age and sex to patients, were enrolled as controls. Single nucleotide polymorphism (SNP) in OPN at nt - 443 and its blood level were analyzed.

Results: The frequency of patients who reached sustained virological response (SVR) was increased in patients with $\mathrm{T} / \mathrm{T}$ at $\mathrm{nt}-443$ than in those with $\mathrm{C} / \mathrm{C}$ or $\mathrm{C} / \mathrm{T}$. Also the frequency of $\mathrm{T}$ allele was increased in responders than in non-responders. However, this increase was not statistically significant. The blood level of OPN was significantly increased in non-responders $(\mathrm{Mean} \pm \mathrm{SD}=37.21 \pm 3.9)$ in comparison to responders (Mean $\pm \mathrm{SD}=33.22 \pm 4.1$ ).

Conclusion: Osteopontin blood level can be considered as a reliable predictor to PEG IFN $\alpha 2 \mathrm{~b}$ plus ribavirin therapy in chronic HCV Saudi Patients.

Keywords: OPN, PEG IFN, HCV, SVR, SNP, RT-PCR.

DOI: https://dx.doi.org/10.4314/ahs.v17i2.10

Cite as: Hussein YM, Alhazmi A, Alzahrani S, El-Askary A, Alghamdy A, Bayomy E, Selim A, Alghamdy M. Osteopontin as a marker for response to Pegylated Interferon Alpha-2b treatment in Chronic HCV Saudi patients. Afri Health Sci. 2017;17(2): 366-372. bttps://dx.doi. org/10.4314/abs.v17i2.10
\end{abstract}

\section{Introduction}

Infection with hepatitis $\mathrm{C}$ virus (HCV) is a common global cause of chronic liver disease, which is also true in Saudi Arabia. HCV prevalence in Saudi Arabia varies in different provinces. The highest of which being the Western and Southern provinces ${ }^{1}$. HCV was responsible for $35.4 \%$ of chronic liver disase among Saudis, $74.2 \%$ among Egyptians, 28.6\% among Yemenis and 24\% among Palestinians ${ }^{2}$. Patients with post-necrotic liver cirrhosis secondary to HCV are also liable to develop hepa-

\section{Corresponding author:}

Ahmad El Askary,

Faculty of Applied Medical Sciences,

Taif Univ., Saudi Arabia

Email: ahmadelaskary3@gmail.com tocellular carcinoma (HCC) with an annual rate of 1 to $4 \% 0^{3,4,5}$.

OPN was shown to be essential for initiation of $\mathrm{T}$ helper 1(Th1) immune response at the upstream of IL-18 and IL-12 in a cytokine network. Th1 immune response is involved in the development of inflammation in chronic hepatitis $\mathrm{C}$, and the hepatocytes infected with HCV are eradicated by Th1 response during IFN-based therapies $^{6}$. Single nucleotide polymorphisms (SNPs) are the most common form of genetic variation that has been employed for the prediction of both disease progression ${ }^{7}$ and therapeutic response ${ }^{8}$. Also, SNP was reported to be associated with a virologic response to IFN-based therapy ${ }^{9}$.

The aim of our study was to analyze OPN protein level in the blood of chronic HCV patients under treatment with interferon (responders and non-responders) and 
their value as pre-treatment predictor of responsiveness to treatment. Also, to compare the results with non-infected patients.

\section{Patients and methods: Patients:}

The present study was an observational case-control study. One hundred individuals were included in this study and divided into two groups; 87 naive chronic HCV-infected Saudi patients and 25 healthy Saudi patients. Patients visited out-patient clinics of Hepatology Department, King Abdul-Aziz Hospital, Taif, Saudi Arabia, during the period from September 2013 to December 2013 and were diagnosed as chronically infected HCV patients. The selection and sampling of patients was done before starting treatment with PEG-IFN, then patients received interferon based therapy at a dose of $1.5 \mathrm{mg} / \mathrm{kg}$ subcutaneously every week plus ribavirin at dose of $600-1200 \mathrm{mg} /$ day, according to the patient's body weight, for 48 weeks. All patients and control gave written informed consent to participate in the study.

The control group enrolled in the study comprised of 25 healthy volunteer subjects with no evidence of any chronic medical condition who matched age and sex with patients. Patients that participated in the study fulfilled the following inclusion criteria: age 18-54 years, elevated alanine transaminase (ALT) and aspartate transaminase (AST); within 6 months prior to entry of the study, positive HCV antibodies, detectable HCV-RNA, $\mathrm{HCV}$ genotype 4, liver biopsy showing histological evidence of chronic hepatitis without cirrhosis or fibrosis, and they were never previously treated with IFN. Patients that presented with liver cirrhosis or hepatocellular carcinoma, haemoglobin $(<11 \mathrm{~g} / \mathrm{dl})$, total leucocytes count $\left(<3000 / \mathrm{mm}^{3}\right)$, neutrophil $\left(<1500 / \mathrm{mm}^{3}\right)$, platelets $(<100$ $000 / \mathrm{mm}^{3}$ ), the presence of anti-nuclear antibodies (titre $<1 / 160$ ), hepatitis B surface antigen seropositivity or auto-immune hepatitis or co-infection with HIV, and the presence of any chronic systemic illness were excluded from this study.

According to response to treatment, patients were classified into two groups: Responders (50 patients) in whom serum HCV-RNA was not detected for 6 months after the discontinuation of IFN-based therapies, they were classified as patients with SVR; and non-responders (37 patients) who received treatment for 6 months and failed to clear the virus as the viral load measurement was assessed by real time PCR. Liver biopsies were evaluated by a single expert pathologist and scored using the Ishak system in separate reports for grading and staging. All the participants in the study were F-0 by Ishak's score.

\section{Methods}

Venous blood samples were collected in ethylene diamine tetraacetic acid (EDTA) and centrifuge tubes. The part in the centrifuge tube was incubated at $37^{\circ} \mathrm{C}$ for 15 minutes, then centrifuged at $3000 \mathrm{rpm}$ for 10 minutes at room temperature. Serum was separated and used for biochemical characterization of $\mathrm{HCV}$ specific antibody titers by enzyme-linked immunosorbent assay and enzymatic evaluation of ALT, AST, bilirubin, albumin and complete blood picture. These tests were performed at weeks one, two, four and monthly thereafter during treatment to detect the development of any adverse side effects to the drugs necessitating dose modification, temporary or permanent stoppage of treatment. Markers of Hepatitis virus: hepatitis B surface antigen, anti-HBc and anti-HCV were assessed by routine methods using commercially available assays.

Viral RNA was extracted using viral RNA extraction kit (Qiagen) and stored at $-80^{\circ} \mathrm{C}$. HCV-RNA titer was measured before and after treatment by real-time PCR by Quanstudio 3 real time PCR system provided by ThermoFisher scientific. Thyroid function tests (T3, T4 and thyroid stimulating hormone) were performed (using Immulite) to all patients before receiving the treatment. Auto-antibodies (anti-nuclear antibodies and anti-DNA) were performed using Immunoflurescence kits.

Quantitative detection of HCV-RNA: Before treatment Quantitative detection of HCV-RNA in serum was measured routinely at weeks 24 and 48 after treatment and graded into low, moderate and high levels. HCVRNA was quantitated in all patients' serum using real time polymerase chain reaction (RT-PCR) (Stratagene, LaJolla, CA, USA). According to quantitative PCR value, we can determine the level of viremia and the response to the treatment. Each patient received sub-cutaneous injection of PEG-IFN-a2b, at $1.5 \mathrm{mg} / \mathrm{kg}$ body weight once a week, combined with daily oral administration of ribavirin at a dosage that was determined on the basis 
of the patient's body weight $(600 \mathrm{mg}$ for $<60 \mathrm{~kg}, 800 \mathrm{mg}$ for $60-80 \mathrm{~kg}$ and $1000-1200 \mathrm{mg}$ for $>80 \mathrm{~kg}$ ). Successful treatment was ascertained on the basis of SVR, defined as HCV RNA-negative 6 months after cessation of therapy.

Estimation of serum osteopontin protein: Human OPN in serum was measured using enzyme-linked immunosorbent assay kit provided by RayBio (RayBiotech, Inc., NY, USA).

Analysis of SNP in the promoter region of OPN at nt - 443: Genomic DNA was extracted from peripheral blood mononuclear using the QIAamp DNA minikit (Qiagen, USA) following the manufacturer's instructions. SNP in the promoter region of OPN, at nt - 443 was determined by direct sequencing of DNA fragments amplified by PCR.

Extracted genomic DNA was amplified in a 50 ul solution (using both forward and reverse primers) with the oligonucleotide primers determined from the sequence of the promoter region of human OPN as follows: Forward 50-TGTCACTAGTGCCATTTGT-30 and reverse 50-TGTACCTTGGTCGGCGTTTG-30 . The reaction mixture was kept at $94^{\circ} \mathrm{C}$ for 3 minutes for the enzyme activation, followed by 35 amplification cycles. Each cycle consisted of denaturation at $94^{\circ} \mathrm{C}$ for 30 seconds, primer annealing at $55^{\circ} \mathrm{C}$ for 30 seconds, and primer extension at $72^{\circ} \mathrm{C}$ for 60 seconds. Then, the mixture was incubated at $72 \mathrm{C}$ for 7 minutes for final primer extension and the PCR products were checked by DNA agarose gel electrophoresis. The PCR amplification product was detected at $630 \mathrm{bp}$. Direct sequencing was performed with the use of The Big Dye Terminator mix V 3.1 system and ABI 310 sequencer (ABI, Lincoln Center Drive Foster City, USA).
Statistical analysis of data: Statistical package for social sciences (IBM-SPSS), version 19 IBMChicago, USA was used for statistical data analysis. Data expressed as mean, standard deviation (SD), number and percentage. Mean and standard deviation were used as descriptive value for quantitative data. Student $t$ test was used to compare the means between two groups, and one-way analysis of variance (ANOVA) test was used to compare means of more than two groups. Number and percentages were used to describe qualitative data. Chi square was used to compare percentages between cases and controls. For all these tests, the level of significance (P-value) was considered significant if $<0.05$.

Informed consent: Written informed consent was obtained from each patient before participating in the study according to the research and ethical committee of Taif university, Taif, Saudi Arabia.

\section{Results}

Demographic and clinical features of subjects included in the study: Among 87 patients, there were 52 $(59.8 \%)$ men and $37(40.2 \%)$ women, aged $40.62 \pm 8.56$ years (mean $\pm \mathrm{SD}$ ), with a range of 18 to 54 years in the twenty five subjects control there were 19 (51.35\%) males and $18(48.65 \%)$ females with an average age of 33.10 \pm 8.16 (mean $\pm \mathrm{SD}$ ). All the patients were genotype $4 \mathrm{a}$ and were treated with PEG-IFN alfa 2-b with a dose of $1.5 \mu \mathrm{g} / \mathrm{kg}$ weekly and ribavirin $(600-1200 \mathrm{mg} /$ day $)$ for 48 weeks. All the included patients were compensated and had no evidence of fibrosis as assessed by clinical, laboratory and imaging investigations. The patients were classified into two groups: responders who included 50 patients and non-responders who included 37 patients. All biochemical tests were significantly higher in hepatitis C patients than control group while there was no significant difference observed regarding age and sex (Table 1). 
Table 1: Demographic and biochemical characteristics of subjects included in the study

\begin{tabular}{|cccc}
\hline & \multicolumn{2}{c|}{ Studied Groups } & \multirow{2}{*}{ Variables } \\
\cline { 2 - 3 } & $\begin{array}{c}\text { Hepatitis C patients (n=87) } \\
\text { Mean } \pm \text { SD }\end{array}$ & $\begin{array}{c}\text { Control (n=25) } \\
\text { Mean } \pm \text { SD }\end{array}$ & value \\
\hline Age & $40.62 \pm 8.56$ & $35.20 \pm 7.35$ & 0.05 \\
Sex & $52(59.8 \%)$ & $15(60 \%)$ & 0.3 \\
Males \% & $35(40.2 \%)$ & $10(40 \%)$ & \\
Females \% & $87.8 \pm 58.2$ & $36 \pm 8.0$ & $\mathrm{P}=0.0001^{*}$ \\
ALT (U/L) & $107 \pm 65.8$ & $33.8 \pm 7.5$ & $\mathrm{P}=0.0001^{*}$ \\
AST (U/L) & $1.43 \pm 0.79$ & $0.83 \pm 0.3$ & $\mathrm{P}=0.0001^{*}$ \\
Total Bilirubin (mg/dl) & $0.46 \pm 0.28$ & $0.19 \pm 0.08$ & $\mathrm{P}=0.0001^{*}$ \\
Direct Bilirubin (mg/dl) & $123.5 \pm 53.4$ & $48.7 \pm 8.6$ & $\mathrm{P}=0.0001^{*}$ \\
Alkaline phosphatase (U/L) & $3.29 \pm 0.45$ & $3.93 \pm 0.53$ & $\mathrm{P}=0.0001^{*}$ \\
Albumin (g/l) & $14.2 \pm 8.3$ & $4.7 \pm 1.8$ & $\mathrm{P}=0.0001^{*}$ \\
Alfa fetoprotein (ng/ml) & $13.5 \pm 1.7$ & $10.1 \pm 0.4$ & $\mathrm{P}=0.0001^{*}$ \\
Prothrombin time (seconds) & $35.21 \pm 4.3$ & $24.3 \pm 8.8$ & $\mathrm{P}=0.0001^{*}$ \\
Osteopontin protein (ng/ml) & & & \\
\hline
\end{tabular}

* Indicate a statistical significant difference

According to the response to PEG-IFN- $\alpha$ 2b plus ribavirin combination therapy, patients were divided into responders $(\mathrm{n}=50)$ and non-responders $(\mathrm{n}=37)$. Patients were considered to be responders if they showed clearance of the virus revealed by negative HCV-RNA after six months of PEG-IFN- $\alpha$ 2b plus ribavirin combination therapy. Interestingly, before starting the PEGIFN- $\alpha 2$ b plus ribavirin combination therapy, responders and non-responders showed no significant difference as regards sex and age. There were 46 responders and 34 non responders. Responders showed significantly lower levels of ALT, AST, ALP, PT, AFP ( $\mathrm{P}<0.05)$ and significantly higher plasma ALB level $(\mathrm{P}=0.01)$ than non-responders. The clinical background features of responders and non-responders before starting therapy were shown in Table (2).

Table 2: Biochemical features between responders and non responders

\begin{tabular}{|cccc|}
\hline \multirow{2}{*}{ Variables } & \multicolumn{2}{c|}{ Studied Groups } & \multirow{2}{*}{ P value } \\
\cline { 2 - 3 } & $\begin{array}{c}\text { Responders (n=50) } \\
\text { Mean } \pm \text { SD }\end{array}$ & $\begin{array}{c}\text { Non responders (n=37) } \\
\text { Mean } \pm \text { SD }\end{array}$ & \\
\hline Age & $41.4 \pm 9.4$ & $42.5 \pm 9.8$ & 0.24 \\
Sex & & & \\
Male & $27(54 \%)$ & $19(51.35 \%)$ & \\
Female & $23(46 \%)$ & $18(48.65 \%)$ & 0.12 \\
ALT (U/L) & $70.2 \pm 33.5$ & $92.4 \pm 29.8$ & $\mathrm{P}=0.000^{*}$ \\
AST (U/L) & $62.7 \pm 28.9$ & $88.3 \pm 37.6$ & $\mathrm{P}=0.000^{*}$ \\
Total Bilirubin (mg/dl) & $0.83 \pm 0.33$ & $0.75 \pm 0.4$ & $\mathrm{P}=0.74$ \\
Direct Bilirubin (mg/dl) & $0.24 \pm 0.21$ & $0.22 \pm 0.24$ & $\mathrm{P}=0.58$ \\
Alkaline phosphatase (U/L) & $93.3 \pm 9.4$ & $96.2 \pm 7.5$ & $\mathrm{P}=0.02^{*}$ \\
Albumin (g/l) & $3.47 \pm 0.31$ & $3.63 \pm 0.27$ & $\mathrm{P}=0.01^{*}$ \\
Alfa fetoprotein (ng/ml) & $10.5 \pm 3.8$ & $10.9 \pm 4.2$ & $\mathrm{P}=0.06$ \\
Prothrombin time (seconds) & $13.3 \pm 2.6$ & $13.8 \pm 1.9$ & $\mathrm{P}=0.004 *$ \\
Osteopontin protein (ng/ml) & $34.75 \pm 6.4$ & $37.82 \pm 4.8$ & $\mathrm{P}=0.0001^{*}$ \\
& & & \\
\hline
\end{tabular}

* Indicate a statistical significant difference 
The genotypes and allele frequencies at the promoter region of osteopontin gene at nt - 443 were significantly different between patients and controls and also between responders and non-responders. In patients who reached sustained virological response (SVR) the frequency of $\mathrm{T} / \mathrm{T}$ genotype at $\mathrm{nt}-443$ was higher than $\mathrm{C} / \mathrm{C}$ or $\mathrm{C} / \mathrm{T}$. Also, the frequency of $\mathrm{T}$ allele was increased in responders than in non-responders. (Table 3)

\section{Table 3: Prevalence of single nucleotide polymorphism (-443) in the promoter region of osteopontin gene and allelle frequency in patients and control}

\begin{tabular}{|c|c|c|c|c|c|c|c|}
\hline \multirow{2}{*}{$\begin{array}{l}\text { SNP at nt - } \\
443\end{array}$} & \multicolumn{4}{|c|}{ Genotypes } & \multicolumn{3}{|c|}{ Allelle frequency } \\
\hline & $\mathrm{C} / \mathrm{C}$ & $\mathbf{C} / \mathbf{T}$ & $\mathbf{T} / \mathbf{T}$ & P-value & C & $\mathbf{T}$ & P-value \\
\hline Patients & $8(9.2 \%)$ & $35(40.2 \%)$ & $44(50.6 \%)$ & & $51(29.3 \%)$ & $123(70.7 \%)$ & \\
\hline Control & $4(16 \%)$ & $13(52 \%)$ & $8(32 \%)$ & $0.22 *$ & $21(42 \%)$ & $29(58 \%)$ & 0.2 \\
\hline Responders & $4(8.0 \%)$ & $20(40 \%)$ & $26(52 \%)$ & & $28(28 \%)$ & $72(72 \%)$ & \\
\hline $\begin{array}{l}\text { Non } \\
\text { responders }\end{array}$ & $4(10.8 \%)$ & $16(43.25 \%)$ & $17(45.95 \%)$ & $0.65^{*}$ & $36(48.65 \%)$ & $38(51.35 \%)$ & 0.7 \\
\hline
\end{tabular}

* The comparison was made between $\mathrm{TT}$ genotype against $\mathrm{C} / \mathrm{T}+\mathrm{C} / \mathrm{C}$ assuming a dominant model

\section{Discussion}

Hepatitis $C$ virus belongs to the genus Hepacivirus, a member of the family Flaviviridae. Until recently it was considered to be the only member of this genus ${ }^{10}$. The majority of HCV infected patients do not clear the virus and this leads to chronic hepatitis which may progresses to liver fibrosis, cirrhosis and hepatocellular carcinoma (HCC) ${ }^{4,5,11}$. The goal of HCV treatment is to cure the virus, which can be done with a combination of drugs. Although the treatment of chronic HCV has now been revolutionized with new drugs, during the time period of conducting the study the treatment protocol of chronic HCV was PEGIFN in combination with ribavirin. Being expensive, involving severe side effects and requiring long treatment duration, the therapy is creating a huge burden on the country. Predictive factors regarding treatment response are not well established for each individual and do not allow personalizing the treatment. Therefore, accurate prediction of response to the therapeutic regimen is of great interest. So, finding genomic based predictors of pre-treatment response to anti-viral therapy is an essential issue $^{12,13}$.

This current therapy is inefficient, mainly due to usually late diagnosis and high recurrence rate within the remaining cirrhotic liver after surgical resection. It is a multistep process involving different genetic alterations that ultimately lead to malignant transformation of hepatocytes. HBV and HCV chronic infections account for $75 \%$ of HCCs, whereas non-viral etiologies such as alcohol and genetic or metabolic disorders represent less than 25\% of cases. HCV-induced chronic liver injury can lead to

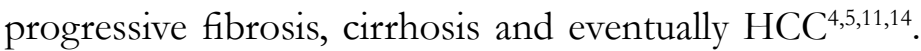
HCV-associated HCC has been reported to promote tumor growth and metastasis due to an increased recurrence after liver resection. However, the underlying mechanisms responsible for metastatic spread of $\mathrm{HCV}$-induced HCC are not fully elucidated ${ }^{15}$.

Osteopontin (OPN) is a secreted phosphoprotein, originally characterized in malignant-transformed epithelial cells. OPN is associated with tumor metastasis of several tumors and over-expressed in hepatocellular carcinoma (HCC $)^{16}$. Importantly, OPN is significantly up-regulated in liver injury, inflammation and HCV- associated HCC. However, the underlying mechanisms of OPN activation and its role in HCV-mediated liver disease pathogenesis are not known ${ }^{15}$. Previous studies have demonstrated that OPN is involved in tumor metastasis and has been detected not only in numerous cancers but also in plasma of HCV related HCC patients, suggesting a correlation between high levels of OPN expression and malignant invasion ${ }^{16,17,18}$. 
Osteopontin is shown to be essential for initiation of Th1 immune response at the upstream of IL-18 and IL-12 in a cytokine network. The Th1 immune response is involved in the development of inflammation in chronic hepatitis $\mathrm{C}$, and the hepatocytes infected with $\mathrm{HCV}$ are eradicated by Th1 response during IFN-based therapies ${ }^{6}$.

In this study, we analyzed OPN blood levels in chronic HCV patients before treatment with interferon, according to their response to interferon they were either (responders or non-responders). and their value as a pretreatment predictor of responsiveness to treatment. The present study was conducted on 87 patients with chronic hepatitis $C$ who received PEG- $\neg$ IFN alpha-2b plus ribavirin. There were 52 men and 35 women, aged $40.62 \pm 8.56$ years, with a range of 18 to 54 years. No significant difference was observed as regards to different genotype distribution between them. The results of the current study revealed that, the sustained virological response (SVR) to PEG-IFN alpha-2b plus ribavirin therapy was $60 \%$. This is comparable with response rate $(63 \%)$ predicted by $\mathrm{Al}$ Ashgar et al., ${ }^{19}$ but is higher compared to that reported by kamal et al., ${ }^{20}$ which was $48 \%$. And is lower compared to that reported by $\mathrm{Al}$ Ashgar et al., ${ }^{21}$ which was (75.6\%).

Results of our study concluded that the allele frequencies but not genotypes at the promoter region of osteopontin gene at $\mathrm{nt}-443$ were significantly different between patients and controls. Frequency of patients who reached sustained virological response (SVR) was increased in patients with $\mathrm{T} / \mathrm{T}$ at $\mathrm{nt}-443$ than in those with $\mathrm{C} / \mathrm{C}$ or $\mathrm{C} / \mathrm{T}$. Also the frequency of $\mathrm{T}$ allele was increased in responders than in non responders. However, the genotypes and allele distribution showed no statistically significant difference between responders and non responders. In the present study, a clear relationship between baseline of OPN protein level in blood of chronic hepatitis $\mathrm{C}$ patients and response to treatment was observed. Lower pre-treatment plasma OPN protein was correlated with better response. This finding is further verified by Huang et al., ${ }^{22}$ study which found that OPN concentrations were significantly increased in the HCV individual with extensive fibrosis and inflammation. They provide evidence that the surveillance of plasma OPN concentration may be a non-invasive biomarker for the evaluation of severity of liver damage in $\mathrm{HCV}$-infected subjects. Other previous results suggest that $\mathrm{HCV}$ infection induces $\mathrm{OPN}$ via altered $\mathrm{Ca}^{+}$homeostasis in the endoplasmic reticulum and elevation of reactive oxygen species in the mitochon- dria. Also, $\mathrm{Ca}^{+}$mediated mitochondrial dysfunction has been suggested to play an important role in HCV-mediated liver disease pathogenesis ${ }^{23}$. In other studies, they observed that the induction of OPN is mediated by the activation of cellular kinases ${ }^{24}$.

Also, Cheng and Mahato ${ }^{25}$ study showed that the OPN might be a central pathway of HSC (hepatic satellite cell) activation. HSC is largely responsible for the development of liver inflammation and cirrhosis in the liver by increasing the ECM (extra cellular matrix) deposition in the sub-endothelial space between hepatocytes and endothelial cells. Our results highlight the correlation between plasma OPN concentration in $\mathrm{HCV}$-infected subjects and response to combination treatment (PEG -INF and ribavirin) of chronic hepatitis $\mathrm{C}$ patients.

\section{Conclusion}

The results of this study proved that osteopontin level but not its SNP at nt - 443 is a good predictor of response to interferon based therapy in Saudi patients with chronic HCV infection.

\section{Acknowledgments}

This study was funded with the support of academic research centre in Taif University, project number 1-4353663.

\section{Conflict of interest}

All the authors declare that there is no conflict of interest regarding publication of this paper.

\section{References}

1. Akbar HO. Hepatitis C virus infection in Saudi Arabia. Saudi J Gastroenterol 2004;10:127-131

2. Shobokshi OA, Serebour FE, Al-Drees AZ, Mitwalli AH, Qahtani A, Skakni LI. Hepatitis C virus seroprevalence rate among Saudis. Saudi Med J. 2003 Jul;24 Suppl 2: 81-86.

3. Di Bisceglie AM. Hepatitis C and hepatocellular carcinoma. Hepatology. 1997 Sep; 26:34-38.

4. Hussein YM, Ghareib AF, Mohamed RH, Radwan MI and Elsawy WH. MAGE-3 and MAGE-4 genes as possible markers for early detection of metastases in hepatitis C virus Egyptian patients complicated by hepatocellular carcinoma. Med Oncol. 2012; Jun;29 (2):994-999.

5. Hussein YM, Morad FE, Gameel MA, Emam WA, El Sawy WH, El Tarhouny SA, Bayomy ES, Raafat N. MAGE-4 gene m-RNA and TGF in blood as potential 
biochemical markers for HCC in HCV-infected patients. Med Oncol. volume 29 issue 5; 2012, 3055 -3062.

6. Ashkar S, Weber G F, Panoutsakopoulou V, Sanchirico M E, Jansson M and Zawaideh S. Eta-1 (osteopontin): an early component of type 1 (cell-mediated) immunity. Science 2000; 287: 860-864.

7. Houldsworth A, Metzner M, Rossol S, Shaw S, Kaminski E, Demaine AG, Cramp ME. Polymorphisms in the IL-12B gene and outcome of HCV infection. J Interferon Cytokine Res. 2005 May;25(5):271-276.

8. Abbas Z, Moatter T, Hussainy A, Jafri W. Effect of cytokine gene polymorphism on histological activity index, viral load and response to treatment in patients with chronic hepatitis C genotype 3. World J Gastroenterol. 2005 Nov 14;11(42):6656-6661

9. Naito M1, Matsui A, Inao M, Nagoshi S, Nagano M, Ito N, Egashira T, Hashimoto M, Mishiro S, Mochida S, Fujiwara K. SNPs in the promoter region of the osteopontin gene as a marker predicting the efficacy of interferon-based therapies in patients with chronic hepatitis C. J Gastroenterol. 2005 Apr;40(4):381-388.

10. Burbelo PD, Dubovi EJ, Simmonds P, Medina JL, Henriquez JA, Mishra N, Wagner J, Tokarz R, Cullen JM, Iadarola MJ, Rice CM, Lipkin WI, Kapoor A. Serology-enabled discovery of genetically diverse hepaciviruses in a new host. J V irol. 2012 Jun;86(11):6171-8. doi: 10.1128/JVI.00250-12. Epub 2012 Apr 4.

11. Hussein YM, Hashim AA, Alzahrani SS, Alhazmi AS, Hawash YA, Eed EM, Shalaby SM. MAGE Genes mRNAs: Potential Early Diagnostic Markers for Hepatocellular Carcinoma in HCV Saudi Patients. IOSR Journal of Dental and Medical Sciences; 2014 Volume 13, Issue 4 Ver. VII., PP 61-65.

12. Saludes V, Bracho MA, Valero O, Ardèvol M, Planas R, González-Candelas F, Ausina V, Martró E. Baseline prediction of combination therapy outcome in hepatitis $\mathrm{C}$ virus $1 \mathrm{~b}$ infected patients by discriminant analysis using viral and host factors. PLoS One. 2010 Nov 30;5(11):e14132. doi: 10.1371/journal.pone.0014132.

13. Ioniţă-Radu F, Raşcanu A, Cheiab B. IL28B polymorphism -- predictive factor of $\mathrm{HCV}$ infected genotype 1 individuals to treatment response and management of therapy. Rom J Intern Med. 2011;49(2):99-104.

14. Farazi PA and De Pinho RA. Hepatocellular carcinoma pathogenesis: from genes to environment. Nat. Rev. Cancer 2006; 6: 674-687.

15. Iqbal J, McRae S, Banaudha K, Mai T, Waris G. Mech- anism of hepatitis $\mathrm{C}$ virus (HCV)-induced osteopontin and its role in epithelial to mesenchymal transition of hepatocytes. J Biol Chem. 2013 Dec 27;288(52):36994-7009. doi: 10.1074/jbc.M113.492314. Epub 2013 Nov 15.

16. Hussein YM, El Askary A, Alhazmi AS, Alzahrani SS, Hashim AA, Bayomy ES, Elesawy BH, Halawani IF and Al Swat MA. Evaluation of Osteopontin (OPN) Blood Level, MAGE-3 and MAGE-4 Genes mRNA as Markers for HCC in Chronic HCV Saudi Patients. Wulfenia Journal. 2014, 21:279-287.

17. Wai PY and Kuo PC. Osteopontin: regulation in tumor metastasis. Cancer Metastasis Rev. 2008; 27:103-118. 18. Cao, D.X.; Li, Z.J.; Jiang, X.O., Lum, Y.L., Khin, E., Lee, N.P., Wu, G.H. and Luk, J.M. Osteopontin as potential biomarker and therapeutic target in gastric and liver cancers. World J. Gastroenterol. 2012; 18, 3923-3930.

19. Al Ashgar H, Helmy A, Khan MQ, Al Kahtani K, Al Quaiz M and Rezeig M. Predictors of sustained virological response to a 48-week course of pegylated interferon alfa-2a and ribavirin in patients infected with hepatitis $C$ virus genotype 4. Ann Saudi Med. 2009; 29: 4-14.

20. Kamal SM, El Tawil AA, Nakano T, He Q, Rasenack $\mathrm{J}$ and Hakam SA. Peginterferon alpha- $2 \mathrm{~b}$ and ribavirin therapy in chronic hepatitis C genotype 4: impact of treatment duration and viral kinetics on sustained virological response. Gut. 2005; 54: 858-866.

21. Al Ashgar H, Khan MQ, Helmy A, Al Swat K, Alshehri A and Al Kalbani A. Sustained Virologic Response to Peginterferon a-2a and Ribavirin in 335 Patients with Chronic Hepatitis C: A Tertiary Care Center Experience. Saudi J Gastroenterol. 2008; 14: 58-65.

22. Huang W, Zhu G, Huang M, Lou G, Liu Y and Wang S. Plasma osteopontin concentration correlates with the severity of hepatic fibrosis and inflammation in HCV-infected subjects, Clinica Chimica Acta. 2010; 411:2 675-678. 23. Piccoli C, Scrima R, Quarato G, D'Aprile A, Ripoli M, Lecce L, Boffoli D, Moradpour D and Capitanio N. Hepatitis $\mathrm{C}$ virus protein expression causes calcium-mediated mitochondrial bioenergetic dysfunction and nitro-oxidative stress. Hepatology 2007; 46:58-65.

24. Zhang J, Yamada O, Matsushita Y, Chagan-Yasutan $\mathrm{H}$ and Hattori T. Transactivation of human osteopontin promoter by human T-cell leukemia virus type 1-enhanced Tax protein. Leuk. Res. 2010; 34:763-768.

25. Cheng $\mathrm{K}$ and Mahato RI. Gene modulation for treating liver fibrosis. Crit Rev Ther Drug Carrier Syst. 2007;24(2):93-146. 